\title{
Survival in Soil of Colletotrichum acutatum and C. gloeosporioides Pathogenic on Strawberry
}

\author{
Stanley Freeman and Zvi Shalev, Department of Plant Pathology, ARO, The Volcani Center, Bet Dagan 50250, \\ Israel; and Jaacov Katan, Department of Plant Pathology and Microbiology, Faculty of Agricultural, Food and En- \\ vironmental Quality Sciences, The Hebrew University of Jerusalem, Rehovot 76100, Israel
}

\begin{abstract}
Freeman, S., Shalev, Z., and Katan, J. 2002. Survival in soil of Colletotrichum acutatum and $C$. gloeosporioides pathogenic on strawberry. Plant Dis. 86:965-970.

The survival ability in soil of different inocula of strawberry isolates of Colletotrichum gloeosporioides and $C$. acutatum was studied under laboratory and field conditions. Two isolates of each species used in this study were identified according to morphological characteristics and by molecular techniques. Conidia of all four isolates survived for up to 1 year in autoclaved soil, whereas viability declined rapidly in untreated soils at $22 \%$ soil moisture (field capacity), with a $95 \%$ reduction in population recorded within 4.0 to 9.8 days. In methyl bromide (MB)treated field soil at field capacity, a 95\% decline in the viability of conidia of the two species was recorded within 8.9 to 12.9 days. At $11 \%$ soil moisture content, the time required for a $95 \%$ population reduction of the isolates of $C$. gloeosporioides and C. acutatum conidia was 124.5 and 114.4 , and 72.8 and 74.2 days, respectively. C. acutatum was not recovered from naturally infected crowns after burial for 5 months in MB-fumigated and untreated soils at 10- and 20-cm depths under field conditions, but the decline was slower in the MB-fumigated soil. However, recovery of the pathogen from artificially inoculated mummified fruit after 5 months of burial ranged from 15 to $39 \%$. Soil solarization for 4 weeks and MB fumigation treatments eradicated the pathogen from buried, artificially inoculated fruits. Based on this study, the potential contribution of conidia as well as mummified fruits to disease epidemics should be considered.
\end{abstract}

Strawberries (Fragaria $\times$ ananassa Duchesne) are cultivated in either open fields or greenhouses as an annual winter crop in warm areas such as California, Florida, and the Mediterranean region $(8,13)$. Transplants for production fields that originate from disease-free material are propagated from mother plants in nurseries in early spring and planted in the autumn, and fruit is harvested throughout the winter and spring of the following year. At the end of the growing season, plants are destroyed, either by mowing off the tops, plowing them into the soil, or applying herbicides (23). Alternatively, plants may be removed individually by uprooting. In all cases, the debris of plants infected by soilborne pathogens may remain in the soil until the next growing season and serve as a potential primary inoculum source for infecting the new crop. It is standard prac-

Corresponding author: S. Freeman

E-mail: freeman@volcani.agri.gov.il

Contribution from the Agricultural Research Organization, Institute of Plant Protection, Bet Dagan, Israel, No. 525/01. This research was supported in part by grant no. IS-2825-97 from BARD, The United States-Israel Binational Agricultural Research and Development Fund.

Accepted for publication 25 April 2002.

Publication no. D-2002-0702-02R

(C) 2002 The American Phytopathological Society tice to fumigate the soil with methyl bromide (MB), which has been reported to eliminate Colletotrichum acutatum (3), before establishing nursery plants and transplants in the field.

Species of the plant-pathogenic fungal genus Colletotrichum (C. acutatum J. H. Simmonds, $C$. fragariae Brooks, and $C$. gloeosporioides (Penz.) Penz. \& Sacc. in Penz.) are responsible for anthracnose and other diseases of strawberry (5,11-13). Morphological criteria such as conidial size and colony morphology are not accurate enough to discriminate between Colletotrichum spp. from strawberry; therefore, a variety of molecular approaches has been used. The GcpR1 repetitive nuclear DNA element (18), A+T-rich DNA (9), arbitrarily primed polymerase chain reaction (ap-PCR), and species-specific PCR analyses $(7,10)$ have been used for reliable differentiation among Colletotrichum spp. responsible for strawberry anthracnose. Accurate identification of species responsible for disease is of paramount importance for pathogen control. For example, in contrast to C. gloeosporioides, C. acutatum isolates are tolerant to the fungicide benomyl (6). Although the predominant species causing root necrosis, crown, and fruit rot of strawberry in Israel is C. acutatum (5), C. gloeosporioides has been isolated on a number of occasions from diseased crowns whose symptoms could not be distinguished from those of crown rot caused by $C$. acutatum.
The origin of the primary inoculum of Colletotrichum spp. in strawberry is in dispute, although transplants are the likely source $(5,13)$. In Louisiana, tissue-cultured plants provided to farmers at the beginning of a growing season remained disease free throughout the nursery and fruiting periods, whereas locally produced plants in nursery soils became infected with $C$. fragariae (15). However, it has been suggested that $C$. acutatum on strawberry may originate from soilborne inoculum and infected crowns, and may overwinter in infected fruit $(3,12,25)$. In California, $C$. acutatum has been reported to survive for 9 months as soilborne propagules attached to strawberry planting stock (3). On the other hand, survival studies of Colletotrichum spp. in infected strawberry crowns have indicated that $C$. gloeosporioides in buried plant debris does not oversummer or contribute to disease epidemics in Florida (23).

In this study, we evaluated the survival in soil of different inocula of C. gloeosporioides and $C$. acutatum under laboratory and field conditions. The experiments were conducted during the critical period of nursery establishment to determine whether the inocula could survive and thus serve as a potential infection source. This was especially important because conflicting reports have been published in this regard and different sources of inoculum have been reported to contribute to pathogen survival and dispersal. A limited control study of $C$. acutatum in buried mummified fruit was also performed in the field, to determine the effectiveness of MB fumigation and soil solarization treatments for eradication of the pathogen.

\section{MATERIALS AND METHODS}

Fungal cultures and growth conditions. Two representative monoconidial isolates, TUT-149 and TUT-5954, of the clonal population of $C$. acutatum in Israel infecting strawberry (5), and two monoconidial isolates, CG-314 and CG-317, of $C$. gloeosporioides (isolated by the authors from infected crowns from Lev Hasharon, Israel) causing crown rot of strawberry, were used in this study. Reference isolates from strawberry used for DNA analysis, $C$. acutatum isolates CA-310 and CA-330, and $C$. gloeosporioides isolates CG-231 and CG-327, previously have been identified and characterized $(5,10)$. The identity of the 
isolates was verified to the species level by PCR-specific primer amplification (7).

All fungi were cultured in the dark on modified Mathur's medium (MS; $0.1 \%$ yeast extract, $0.1 \%$ bactopeptone, $1 \%$ sucrose, $\quad 0.25 \% \quad \mathrm{MgSO}_{4} 7 \cdot \mathrm{H}_{2} \mathrm{O}, \quad 0.27 \%$ $\mathrm{KH}_{2} \mathrm{PO}_{4}, 2 \%$ agar; 22) for formation of conidia to be used in soil survival studies and fruit inoculations. When necessary, for semiselective isolation of Colletotrichum spp., the medium was amended with $2.5 \mu \mathrm{g}$ a.i. of iprodione (Rovral 50WP; Rhone Poulenc, France), $0.1 \%$ lactic acid, and 25 $\mathrm{mg}$ of ampicillin in 1 liter of sterile distilled water (5).

DNA extraction and PCR amplification. Fungal DNA was extracted and purified as previously described (9). The DNA was dissolved in $0.5 \mathrm{ml}$ of TE buffer (10 mM Tris-HCl, $1 \mathrm{mM}$ EDTA; $\mathrm{pH}$ 8.0) to an approximate concentration of 200 to 500 $\mu \mathrm{g} / \mathrm{ml}$ and diluted to a concentration of 10 to $100 \mathrm{ng} / \mu \mathrm{l}$ for PCR reactions. PCR primers for speciation included the internal transcribed spacer (ITS) 4 primer (TCCTCCGCTTATTGATATGC) coupled with the specific primer for $C$. acutatum (CaInt2; GGGGAAGCCTCTCGCGG) or for C. gloeosporioides (CgInt; GGCCTC CCGCCTCCGGGCGG) (1). PCR was performed as previously described (7). Amplification products were separated by electrophoresis in agarose gels $(1.8 \%$ $\mathrm{wt} / \mathrm{vol} ; 15-\mathrm{cm}$ width by $10-\mathrm{cm}$ length) in Tris-acetate-EDTA buffer at $80 \mathrm{~V}$ for $2 \mathrm{~h}$ (19), stained with ethidium bromide, and viewed under UV light to detect amplification products.

Survival of $C$. acutatum and $C$. gloeosporioides in treated soils under controlled conditions. A sandy soil (92\% sand, $8 \%$ clay, $\mathrm{pH} 7.0$; field capacity $22 \%$ ) was obtained from a strawberry field in the Sharon area of central Israel and used as the untreated control. The MB-treated soil was fumigated at $500 \mathrm{~kg} / \mathrm{ha}$ and autoclaved soil was sterilized by autoclaving twice for $30 \mathrm{~min}$ at 24 -h intervals. The soil was filtered through a $2-\mathrm{mm}$ sieve before inoculation and $50 \mathrm{~g}$ of the filtered soil was placed in 100-ml Erlenmeyer flasks. Aqueous suspensions of $C$. acutatum (isolates TUT5954 and TUT-149) and C. gloeosporioides (isolates CG-314 and CG-317) were thoroughly mixed with the soil to a final concentration of $10^{5}$ conidia/g of soil, and the soil was adjusted to field capacity ( $22 \%$ moisture content). Survival of naturally produced inoculum from two infected fruits (cv. Malach, susceptible to $C$. $a c u$ tatum) also was determined in control soil. To determine the effect of moisture content on survival of conidia, the soil was dried at room temperature and adjusted to $11 \%$ moisture content after inoculation. Each isolate was introduced into three replicate flasks containing autoclaved, MB-treated, and untreated control soils. The flasks containing the inoculum were incubated at $25^{\circ} \mathrm{C}$ in the dark. Samples of $1 \mathrm{~g}$ of soil were removed every 3 days for 2 weeks and thereafter on a monthly basis, suspended in $9 \mathrm{ml}$ of sterile distilled water, and plated in serial dilutions on amended MS to determine the number of CFU of Colletotrichum per gram of soil. Survival over time was calculated as a percentage of the original inoculum at zero time, and expressed as the number of days needed to recover 50 and $5 \%$ of the original population. Survival percentages were calculated according to the regression equations of the survival versus time curve for each isolate. Linear regression was used to determine changes in conidial survival over time in the different soil treatments. The analysis was performed separately for each isolate. The dependent variable in the analysis was expressed as $\log$ CFU with the independent variable being time. The regression equations were calculated for each of three replicates per isolate. The regression equations were used to calculate the time at which population size declined by 50 and $95 \%$ of the original population. These values were defined as survival time $\mathrm{S}_{50}$ and $\mathrm{S}_{5}$, respectively. The survival values were calculated for each isolate replication. Analysis of variance was used to compare $\mathrm{S}_{50}$ and $\mathrm{S}_{5}$ values between the different replications according to Fisher's protected least significant difference (LSD) test $(P \leq$ 0.05), using SigmaStat software (ver. 2.03; Jandel Corp., San Rafael, CA). Survival experiments were conducted at least twice.

Preparation of $C$. acutatum-infected mummified fruit and collection of naturally infected crowns. Healthy, 3- to 4week-old green fruit, measuring 1 to 1.5 $\mathrm{cm}$ in length (cv. Malach), were obtained from the Sharon area for inoculation purposes. The fruit were surface sterilized by submerging in $3 \%$ sodium hypochlorite (Sigma, Rehovot, Israel) for $2 \mathrm{~min}$, rinsed twice with sterile water, and dried in a laminar flow hood before inoculation. The fruit were artificially inoculated by dipping for $5 \mathrm{~min}$ in a conidial suspension of isolate TUT-149 at a concentration of $5 \times 10^{6}$ conidia/ml, and were incubated at $25^{\circ} \mathrm{C}$ for $72 \mathrm{~h}$ in a moisture chamber. The fruit then were dried at room temperature for 30 days until mummification. Prior to burial, infection of the mummified fruit was verified by plating 30 surface-sterilized fruit on amended MS medium. All the mummified fruit were infected by $C$. acutatum. $C$. gloeosporioides was not used in this study in order to limit fungal spread, because this organism is not the major Colletotrichum spp. affecting strawberry in Israel.

In May 1997 and 1998, a sample of approximately 100 wilted plants (cv. Malach) from two fields in the Sharon area exhibiting approximately 50\% crown rot were plated on the amended MS medium to determine percent infection. C. acutatum was recovered from all the sampled crowns, which were subsequently used for survival experiments in the field.
Survival of $C$. acutatum in infected crowns and mummified fruit under field conditions. Two field experiments to evaluate $C$. acutatum survival in naturally infected crowns and in artificially produced mummified fruit were conducted in the Sharon area in a cultivated pepper field adjacent to a strawberry nursery in order to avoid contamination and infection of plants in the nursery. Agronomic conditions in the pepper field were similar to those in the strawberry nursery. The experiments began on 1 June 1997 and 6 June 1998, and terminated on 30 October 1997 and 2 November 1998, respectively. The inocula were buried in either untreated or MBfumigated moist soil, under a daily dripirrigation regime, to mimic the conditions in a strawberry nursery. Individual crowns and infected mummified fruits were placed in $250-\mu \mathrm{m}$ nylon mesh bags containing 100 $\mathrm{g}$ of moist soil, either untreated or MBfumigated, from the burial sites. Each bag contained either 10 crowns or 10 fruit. The bags were buried at two depths, 10 and 20 $\mathrm{cm}$, in the same location in a randomized design. Every 14 days or once a month over a 5-month period, three replicate bags per depth and per soil treatment were removed from the soil. The crowns and fruit were retrieved and washed under running tap water, surface sterilized in $3 \%$ sodium hypochlorite for $2 \mathrm{~min}$, rinsed in sterile distilled water for $1 \mathrm{~min}$, dried in a laminar flow hood, and placed on plates containing amended MS medium. The plates were incubated at $25^{\circ} \mathrm{C}$ in the dark for 5 to 7 days. Percent survival was determined by calculating the number of infected crowns or fruit that yielded C. acutatum growth on the medium out of the total number plated. Means of 30 fruit or crowns per soil type and depth were calculated. Soil temperatures were measured daily throughout the experimental periods using a datalogger (HTEA; United Instruments, Haifa, Israel), and minimum and maximum temperatures for 10- and 20-cm depths were recorded.

Control of $C$. acutatum in mummified fruits by MB fumigation and soil solarization under field conditions. The MB fumigation experiment was conducted during the first week of May 1997, which coincides with the nursery establishment period, in a plot destined for a strawberry nursery in the Sharon area in Israel. Solarization was performed in the same area during the summer in July 1998, as previously described (21). The mummified fruit were buried in the soil prior to MBfumigation $(500 \mathrm{~kg} / \mathrm{ha})$ or solarization, and in an untreated, control soil located adjacent to the experimental site. Ten infected mummified fruit were placed in nylon mesh bags with $100 \mathrm{~g}$ of moist soil from the burial sites. Bags then were placed on the soil surface or buried at two depths, 10 and $20 \mathrm{~cm}$, in the same location in a randomized design. The bags were sampled from MB-treated and untreated soils 2 days 
after fumigation and from solarized and untreated soils 4 weeks after treatment. For each sampling period, three replicate bags per depth and per treatment were removed from the soil. Subsequently, the fruit were washed under running tap water, surface sterilized in $3 \%$ sodium hypochlorite for 2 min, rinsed in sterile distilled water for 1 min, dried in a laminar flow hood, and placed on plates containing amended MS medium. The plates were incubated at $25^{\circ} \mathrm{C}$ in the dark for 5 to 7 days. Percentage of survival was determined by calculating the proportion of infected crowns or fruit yielding $C$. acutatum out of the total number plated. Means of 30 fruit or crowns per soil type and depth were calculated. Analysis of variance was used to compare percentage survival among the different treatments using Fisher's protected LSD test $(P \leq 0.05)$. Soil temperatures were measured daily throughout the experimental periods as already described.

\section{RESULTS}

Identification of Colletotrichum isolates. The isolates used in this study were identified by morphological characteristics according to size of conidia produced on MS medium and by molecular methods. Conidia of $C$. gloeosporioides isolates $\mathrm{Cg}$ 314 and CG-317 were cylindrical with obtuse ends and measured 13 to $24 \mu \mathrm{m}$ in length, whereas conidia of the $C$. acutatum strawberry isolates were elliptical-fusiform, tapered and acute at both ends, and measured 13 to $20 \mu \mathrm{m}$ in length (11). DNA from the $C$. acutatum strawberry isolates used in this study (TUT-5954 and TUT149) and from representative isolates CA310 and CA-330 from the United States was amplified by the species-specific primers, yielding a product of $490 \mathrm{bp}$, but was not amplified by the $C$. gloeosporioides-specific primers (Fig. 1A). Similarly, DNA from the $C$. gloeosporioides strawberry isolates (CG-314 and CG-317) and from representatives CG231 and CG-327 was amplified by its species-specific primers, yielding a product of $450 \mathrm{bp}$, but was not amplified by the $C$. acutatum-specific primers (Fig. 1B). The morphological and molecular assays verified the isolates to the species level.

Survival of $C$. acutatum and $C$. gloeosporioides in autoclaved, untreated, and fumigated soil. In autoclaved field soil, there was an increase (of approximately 100-fold) in CFU during the first month, then a decline to their original density 70 to 100 days after inoculation (Fig. 2). All four isolates survived up to 1 year with at least 1,000 propagules/g of soil remaining. Although the four isolates differed in percent survival after 200 days, no significant differences in population density were observed among the isolates at the end of the experiment, or between the two Colletotrichum spp.

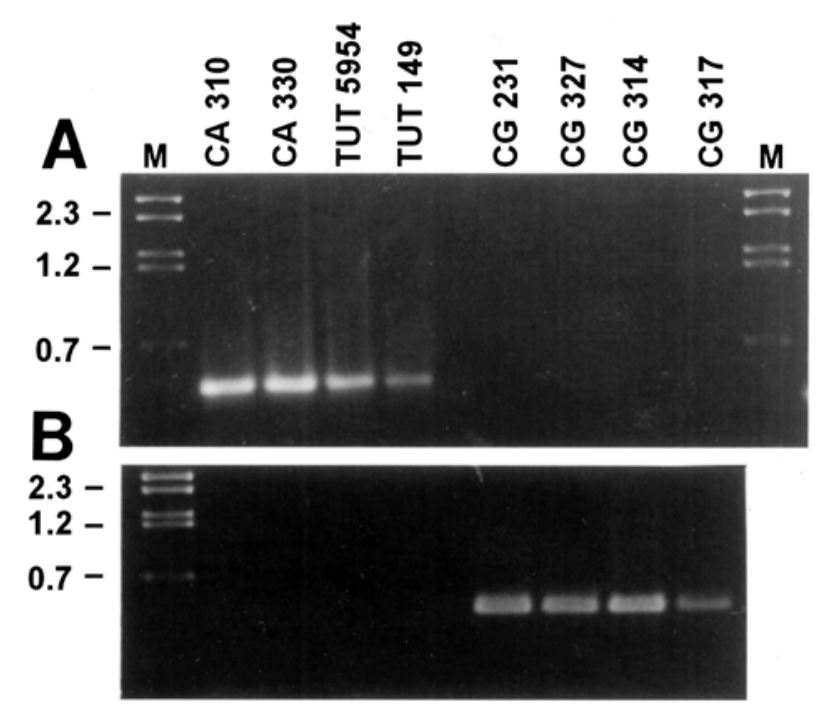

Fig. 1. Polymerase chain reaction amplification products using species-specific primers for A, Colletotrichum acutatum and B, C. gloeosporioides of genomic DNA from C. acutatum (isolates CA-310, CA-330, TUT-5954, and TUT-149) and C. gloeosporioides (isolates CG-231, CG-327, CG-314, and CG-317) from strawberry. C. acutatum- and C. gloeosporioides-specific products of 490 and $450 \mathrm{bp}$ (A and B, respectively) were amplified. Lane M: DNA markers with sizes in kilobases.

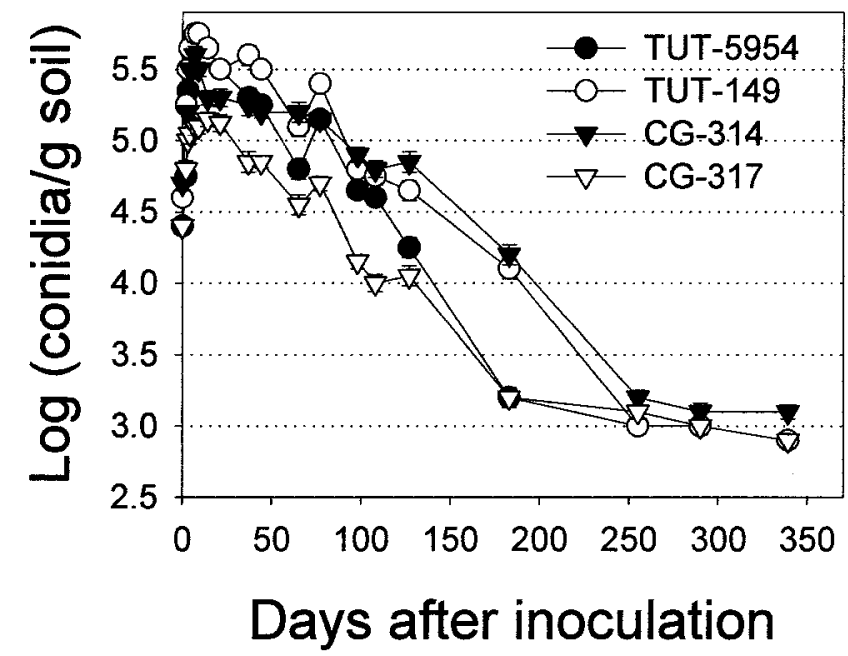

Fig. 2. Survival of Colletotrichum acutatum (isolates TUT-5954 and TUT-149) and C. gloeosporioides (isolates CG-314 and CG-317) in sterilized soil expressed as CFU over time. Bars represent standard errors of the mean. Where bars are lacking, the error is less than $5 \%$ of the value of the point. Values are means of survival of isolates from three replicate flasks.

Table 1. Survival, expressed as number of days needed to recover $50 \%\left(\mathrm{~S}_{50}\right)$ and $5 \%\left(\mathrm{~S}_{5}\right)$ of the original population, of culture-produced conidia and natural inoculum of Colletotrichum gloeosporioides and C. acutatum in untreated field soil, under controlled conditions in two experiments

\begin{tabular}{lccccc}
\hline & \multicolumn{5}{c}{ Survival (days) $^{\mathbf{z}}$} \\
\cline { 2 - 3 } \cline { 5 - 6 } Species and isolates & \multicolumn{3}{c}{ Exp. 1 } & & \multicolumn{2}{c}{ Exp. 2 } \\
\cline { 2 - 3 } \cline { 5 - 6 } C. gloeosporioides (314) & $\mathbf{S}_{\mathbf{5 0}}$ & $\mathbf{S}_{\mathbf{5}}$ & & $\mathbf{S}_{\mathbf{5 0}}$ & $\mathbf{S}_{\mathbf{5}}$ \\
C. gloeosporioides (317) & $5.7 \mathrm{~b}$ & $4.4 \mathrm{a}$ & & $5.5 \mathrm{a}$ & $9.8 \mathrm{a}$ \\
C. acutatum (TUT-149) & $3.7 \mathrm{~b}$ & $5.9 \mathrm{a}$ & & $3.7 \mathrm{~b}$ & $4.4 \mathrm{bc}$ \\
C. acutatum (TUT-5954) & $3.3 \mathrm{~b}$ & $4.0 \mathrm{a}$ & & $5.5 \mathrm{a}$ & $5.8 \mathrm{~b}$ \\
C. acutatum (natural 1) & $2.3 \mathrm{~b}$ & $5.4 \mathrm{a}$ & & $6.1 \mathrm{a}$ & $6.6 \mathrm{~b}$ \\
C. acutatum (natural 2) & $2.3 \mathrm{~b}$ & $3.4 \mathrm{~b}$ & & $3.1 \mathrm{~b}$ & $4.2 \mathrm{c}$ \\
\hline
\end{tabular}

${ }^{\mathrm{z}}$ Survival percentages were calculated from linear regressions of survival on time for each isolate or source. All regressions were significant $(P<0.05)$ and $R^{2}$ values ranged from 0.89 to 0.98 . Values within each column followed by a common letter are not significantly different $(P>0.05)$ according to Fisher's protected least significant difference test. 
In untreated soil, the decline in the viability of conidia from the two species and inoculum types was very rapid, resulting in a $50 \%$ reduction in CFU within 2.3 to 6.1 days in two separate experiments (Table 1). Likewise, the time required for a $95 \%$ reduction in population (5\% survival) ranged from 3.4 to 9.8 days, although the survival of naturally produced conidia declined significantly faster than those produced on artificial medium.

In MB-treated field soil under controlled conditions, the decline in the viability of conidia of the two species was very rapid at field capacity, resulting in a $50 \%$ reduction in CFU within 6.3 to 6.9 days (Table 2). Similarly, the time required for a $95 \%$ reduction in population ranged from 8.9 to 12.9 days, with no significant difference

Table 2. Survival, expressed as number of days needed to recover 50\% $\left(\mathrm{S}_{50}\right)$ and $5 \%\left(\mathrm{~S}_{5}\right)$ of the original population, of culture-produced conidia of Colletotrichum gloeosporioides and C. acutatum in methyl bromide-treated field soil at two soil moisture levels at $25^{\circ} \mathrm{C}$

\begin{tabular}{|c|c|c|c|c|}
\hline \multirow[b]{3}{*}{ Species and isolates } & \multicolumn{4}{|c|}{ Survival (days) ${ }^{\mathbf{z}}$} \\
\hline & \multicolumn{2}{|c|}{$11 \%$ Moisture } & \multicolumn{2}{|c|}{$22 \%$ Moisture } \\
\hline & $S_{50}$ & $\mathbf{S}_{5}$ & $\mathbf{S}_{\mathbf{5 0}}$ & $\mathbf{S}_{5}$ \\
\hline C. gloeosporioides (314) & $31.7 \mathrm{a}$ & $124.5 \mathrm{a}$ & $6.5 \mathrm{a}$ & $12.9 \mathrm{a}$ \\
\hline C. gloeosporioides (317) & $15.0 \mathrm{~b}$ & $114.4 \mathrm{a}$ & $6.9 \mathrm{a}$ & $10.3 \mathrm{a}$ \\
\hline C. acutatum (TUT-149) & $15.6 \mathrm{~b}$ & $72.8 \mathrm{~b}$ & $6.8 \mathrm{a}$ & $11.7 \mathrm{a}$ \\
\hline C. acutatum (TUT-5954) & $15.9 \mathrm{~b}$ & $74.2 \mathrm{~b}$ & $6.3 \mathrm{a}$ & $8.9 \mathrm{a}$ \\
\hline
\end{tabular}

${ }^{\mathrm{z}}$ Survival percentages were calculated from linear regressions of survival on time curves for each isolate or source. All regressions were significant $(P<0.05)$ and $R^{2}$ values ranged from 0.88 to 0.99 . Values within each column followed by a common letter are not significantly different $(P>$ 0.05 ) according to Fisher's protected least significant difference test.

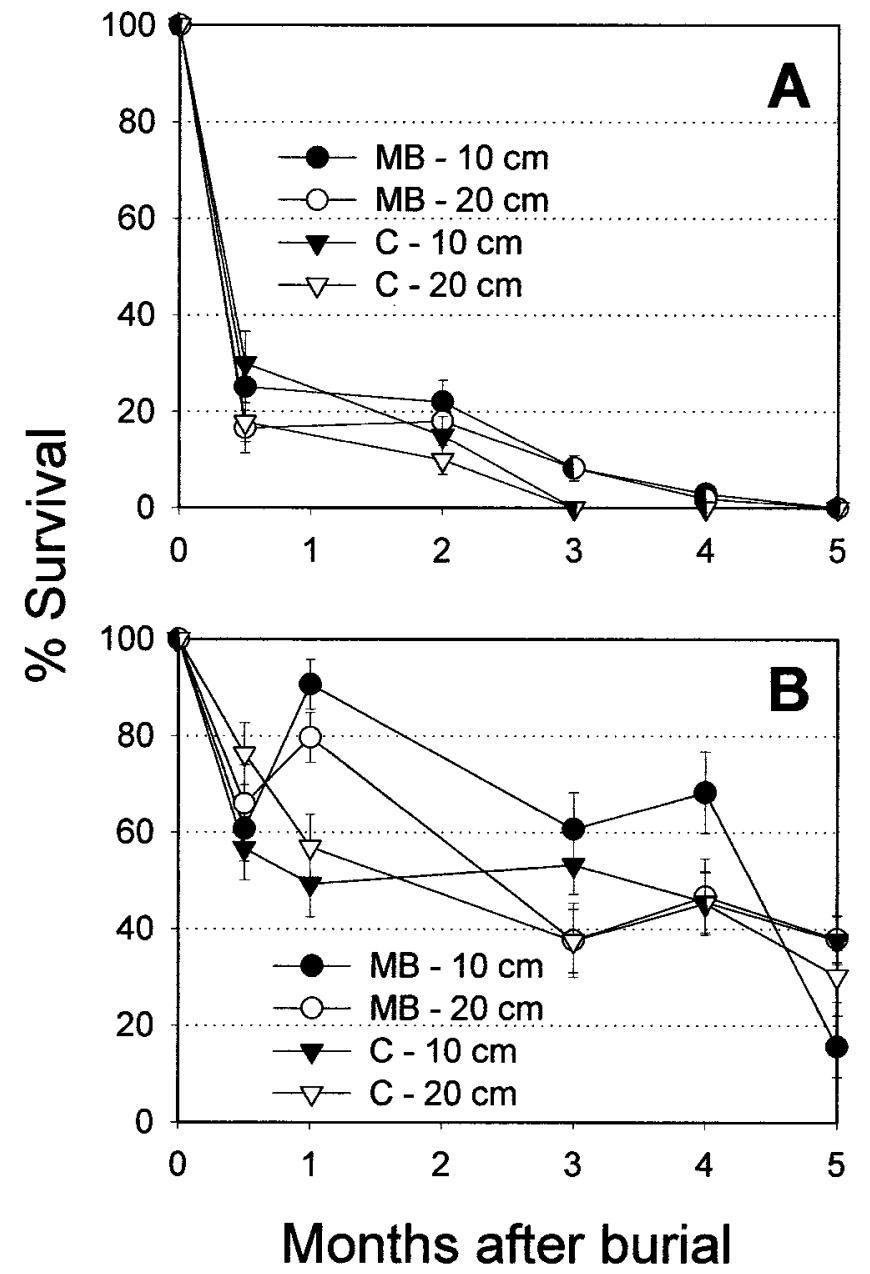

Fig. 3. Percent survival of Colletotrichum acutatum in A, naturally infected strawberry crowns and B, artificially inoculated mummified strawberry fruit under field conditions over time. The inocula were buried in methyl bromide (MB)-fumigated and $\mathbf{C}$, untreated soil at 10- and 20-cm depths. Bars represent standard errors of the mean. Where bars are lacking, the error is less than $5 \%$ of the value of the point. Values are means of three replicates containing 10 crowns or fruit per sampling period. among the tested populations. However, at $11 \%$ soil moisture content, considerably more conidia of both $C$. acutatum and $C$. gloeosporioides survived than at $22 \%$ (Table 2). This difference was especially pronounced when measuring the time required for the decline to $5 \%$ survival of $C$. gloeosporioides, relative to that of $C$. acutatum (Table 2). Survival rates for $C$. gloeosporioides $\mathrm{CG}-314$ and $\mathrm{CG}-317$ were significantly higher than those of $C$. acutatum TUT-5954 and TUT-149, registering 124.5 and 114.4 days compared with 72.8 and 74.2 for the remaining $5 \%$ of each population, respectively (Table 2 ). The decline in the populations of the four isolates in MBtreated soil at field capacity (Table 2) was slower than in untreated field soil (Table 1).

Survival of $C$. acutatum in naturally infected crowns and artificially inoculated mummified fruit in soil under field conditions. Temperatures recorded in the soil from June until October at the two depths ranged from $24 \pm 3$ to $27 \pm 3^{\circ} \mathrm{C}$. At the time of burial, $C$. acutatum was recovered from $100 \%$ of the crowns and fruit after surface sterilization.

In 1997, the pathogen in the crowns declined rapidly in both untreated and MBtreated soils and at both depths (Fig. 3A). After 2 weeks of burial at $10-$ and $20-\mathrm{cm}$ depths, only 17 and $33 \%$ of the crowns, respectively, harbored the pathogen, with a further decline in crown infection after 2 months to between 10 and $20 \%$ recovery (Fig. 3A). After 3 months, the pathogen was not detected in crowns from untreated soil at either depth, but was recovered from 10 and $11 \%$ of crowns buried in MBtreated soil at $10-$ and $20-\mathrm{cm}$ depths, respectively (Fig. 3A). After 4 months of burial, the pathogen was detected at low levels in 2 to $3 \%$ of the crowns in the MBtreated soil; whereas, after 5 months, the pathogen was not recovered from any of the crown samples. A similar trend was obtained in 1998; after 2 months, 15 and $10 \%$ of the crowns at $10-$ and $20-\mathrm{cm}$ depths, respectively, harbored the pathogen in the untreated soil. The comparable figures for the MB-treated soil were 22 and $18 \%$. After 3 months, the pathogen could not be recovered from crowns in the untreated soils at either depth; whereas, in the MB-treated soil, pathogen recovery was 10 and $11 \%$ after 3 months and 3 and $2 \%$ after 4 months at $10-$ and $20-\mathrm{cm}$ depths, respectively.

In 1997, the pathogen in mummified fruit declined less rapidly than in crowns, maintaining various levels of viability in both soils at $10-$ and $20-\mathrm{cm}$ depths after 5 months of incubation (Fig. 3B). After 2 weeks of incubation in both soils, at 10and $20-\mathrm{cm}$ depths, 50 to $85 \%$ of the mummified fruit harbored the pathogen, with a gradual decline in fruit infection after 3 months to between 38 and $60 \%$ recovery (Fig. 3B). Recovery of the pathogen after 5 
months of incubation ranged from 15 to $39 \%$. In 1998, a similar trend was observed. The pathogen was recovered from the mummified fruit (32 to $82 \%$ ) after 5 months of soil incubation, but the variation between samples was large. However, in both experiments, survival of the pathogen in mummified fruit was greater than in the crowns.

Control of $C$. acutatum in buried mummified fruit by fumigation and solarization. Mummified fruit were placed on the soil surface or buried to a depth of 10 or $20 \mathrm{~cm}$ in field soil. MB fumigation and soil solarization were conducted to determine the efficacy of pathogen control. Treatments by MB fumigation or solarization of the infected fruit at all soil depths were very effective in pathogen control; the reduction in pathogen recovery ranged from 94 to $100 \%$ in solarized soil (Table 3) and $100 \%$ in the MB-treated soil (Table 4). Although a steady decline in recovery of the pathogen from mummified fruit in untreated soil was observed, pathogen recovery remained significantly higher than in the other treatments (Table 3 ).

\section{DISCUSSION}

It is well established that disease-free plants are essential for the management of strawberry anthracnose and crown rot caused by Colletotrichum spp. $(15,20,23)$. However, inoculum can originate from other sources, such as soil, plant debris, contaminated clothing, and other plant hosts, and initiate disease (16). This study shows the varying survival capabilities in soil of different types of inoculum of Colletotrichum spp. from strawberry. This issue is of importance because such inoculum may serve as a potential source for disease outbreak.

Conidia of $C$. gloeosporioides and $C$. acutatum in sterilized soil survived for at least 1 year; such conditions may be comparable to those prevailing after steaming, where a considerable "biological vacuum" can develop. Conidial survival in natural field soil was limited to a number of days (Table 1). However, survival was prolonged in MB-fumigated field soil, where microbial activity is lower, and ranged

Table 3. Survival of Colletotrichum acutatum in mummified fruit after 4 weeks in solarized or untreated soil under field conditions

\begin{tabular}{lcc}
\hline Treatments $^{\mathbf{y}}$ & $\begin{array}{c}\text { Soil depth } \\
(\mathbf{c m})\end{array}$ & $\begin{array}{c}\text { Survival } \\
(\boldsymbol{\%})^{\mathbf{z}}\end{array}$ \\
\hline Untreated & 10 & $40.0 \mathrm{a}$ \\
Untreated & 20 & $46.0 \mathrm{a}$ \\
Solarization & 10 & $6.0 \mathrm{~b}$ \\
Solarization & 20 & $0.0 \mathrm{~b}$ \\
\hline
\end{tabular}

y Control inoculum was buried in untreated field plots.

z Values within each column followed by a common letter are not significantly different $(P>0.05)$ according to Fisher's protected least significant difference test. from 2 to 4 months (Table 2), depending on the species. In this study, no resting structures of C. acutatum and C. gloeosporioides were detected. However, sclerotial formation has been reported in $C$. acutatum infecting leatherleaf fern (16) and in C. coccodes infecting tomato (2), which may prolong survival of the pathogen.

The ability of the strawberry anthracnose pathogen to survive for extended periods in MB-fumigated soil, as shown in this work, is of practical importance to farmers, because MB fumigation of strawberry nursery soils before planting is a common practice. Therefore, potential infections in developing daughter plants may stem from splash dispersal of inocu$\operatorname{lum}(14,17)$ in such soil, or from contaminated tools, workers' clothes, or infected plant material $(16,20)$. MB usage will be banned in 2005 and most likely will be replaced by other fumigants, such as metam sodium. It would be interesting to determine whether such fumigated soils also can improve survival of Colletotrichum spp. No significant differences in survival were observed between the two Colletotrichum spp., except for C. gloeosporioides in MB-fumigated soil at the lower moisture content. This may indicate improved fitness in terms of $C$. gloeosporioides survival in soil relative to $C$. acutatum as was demonstrated in Florida, where $C$. gloeosporioides is the predominant crown rot pathogen of strawberry and C. acutatum is considered the major foliar and fruit rot pathogen (23). It should be noted, however, that an increase in the moisture content of MB-fumigated soil, from 11 to $22 \%$, was detrimental to the survival of conidia of both C. gloeosporioides and $C$. acutatum, further corroborating the importance of soil moisture on viability of Colletotrichum spp. from strawberry and other crops $(4,16,24,26)$.

$C$. fragariae and $C$. acutatum also are able to overwinter in infected crowns and fruit, respectively $(12,25)$, and $C$. acutatum has been reported to survive for 9 months in soil attached to plants (3), demonstrating the inoculum potential. In this study, $C$. acutatum in artificially inoculated fruit buried in soil survived longer (at least 5

Table 4. Survival of Colletotrichum acutatum in mummified fruits after 2 days in methyl bromide (MB)-treated or untreated soil under field conditions

\begin{tabular}{lcr}
\hline Treatments $^{\mathbf{y}}$ & $\begin{array}{c}\text { Soil depth } \\
(\mathbf{c m})\end{array}$ & $\begin{array}{c}\text { Survival } \\
(\boldsymbol{\%})^{\mathbf{z}}\end{array}$ \\
\hline Untreated & $0,10,20$ & $100.0 \mathrm{a}$ \\
MB & $0,10,20$ & $0.0 \mathrm{~b}$ \\
\hline
\end{tabular}

y Control inoculum was buried in untreated field plots.

z Values within each column followed by a common letter are not significantly different $(P>0.05)$ according to Fisher's protected least significant difference test. months) than in naturally infected crowns (up to 3 months). These results further emphasize the importance of inoculum type, which can determine the potential of disease outbreak and, in the case of infected fruit, may permit oversummering of the pathogen and infection of the autumn fruiting crop, similar to the overwintering of $C$. acutatum inoculum in infected fruit and infection of the spring crop in Ohio (25).

In this study, $C$. acutatum in naturally infected crowns did not appear to have potential as an inoculum source for anthracnose epidemics in Israel due to its limited survival, but further studies to verify this need to be conducted. However, the pathogen survived for extended periods in fruit under field conditions. Moreover, conidia of both C. acutatum and C. gloeosporioides remained viable for extended periods under lower moisture conditions in MB-fumigated soils. Therefore, the contribution of these inocula to disease outbreaks should be considered because the period between cultivations of the fruiting crop is approximately 4 months; termination in May to June and new plantings in September to October. The limited control experiments conducted in this study further demonstrated the effectiveness of $\mathrm{MB}$ as well as solarization in the eradication of $C$. acutatum in soil. Therefore, solarization may be implemented instead of MB as an alternative means of control. Although the predominant anthracnose pathogen in Israel is C. acutatum (5), C. gloeosporioides has been isolated from diseased plants; therefore, establishment of this species should be considered.

\section{ACKNOWLEDGMENTS}

We thank D. Shtienberg for advice regarding statistical analyses of the data and A. Gamliel for advice regarding the soil solarization experiments.

\section{LITERATURE CITED}

1. Brown, A. E., Sreenivasaprasad, S., and Timmer, L. W. 1996. Molecular characterization of slow-growing orange and Key lime anthracnose strains of Colletotrichum from citrus as C. acutatum. Phytopathology 86:523527.

2. Dillard, H. R., and Cobb, A. C. 1998. Survival of Colletotrichum coccodes in infected tomato tissue and in soil. Plant Dis. 82:235-238.

3. Eastburn, D. M., and Gubler, W. D. 1990. Strawberry anthracnose: detection and survival of Colletotrichum acutatum in soil. Plant Dis. 74:161-163.

4. Eastburn, D. M., and Gubler, W. D. 1992. Effects of soil moisture and temperature on the survival of Colletotrichum acutatum. Plant Dis. 76:841-842.

5. Freeman, S., and Katan, T. 1997. Identification of Colletotrichum species responsible for anthracnose and root necrosis of strawberry in Israel. Phytopathology 87:516-521.

6. Freeman, S., Katan, T., and Shabi, E. 1998. Characterization of Colletotrichum species responsible for anthracnose diseases of various fruits. Plant Dis. 82:596-605.

7. Freeman, S., Minz, D., Maymon, M., and Zveibil, A. 2001. Genetic diversity within Colletotrichum acutatum sensu Simmonds. 
Phytopathology 91:586-592.

8. Freeman, S., and Nicoli, G. 1999. Implementation of IPM: Strawberries. Pages 454-472 in: Integrated Pest and Disease Management in Greenhouse Crops. L. Gullino, J. van Lenteren, and Y. Elad eds., Kluwer Academic Publishers, Dordrecht, The Netherlands.

9. Freeman, S., Pham, M., and Rodriguez, R. J. 1993. Molecular genotyping of Colletotrichum species based on arbitrarily primed PCR, A + T-rich DNA, and nuclear DNA analyses. Exp. Mycol. 17:309-322.

10. Freeman, S., and Rodriguez, R. J. 1995. Differentiation of Colletotrichum species responsible for anthracnose of strawberry by arbitrarily primed PCR. Mycol. Res. 99:901905.

11. Gunnell, P. S, and Gubler, W. D. 1992. Taxonomy and morphology of Colletotrichum species pathogenic to strawberry. Mycologia 84:157-165.

12. Horn, N. L., and Carver, R. B. 1968. Overwintering of Colletotrichum fragariae in strawberry crowns. Phytopathology 58:540-541.

13. Howard, C. M., Maas, J. L., Chandler, C. K., and Albregts, E. E. 1992. Anthracnose of strawberry caused by the Colletotrichum com- plex in Florida. Plant Dis. 76:976-981.

14. Madden, L. V., Yang, X., and Wilson, L. L. 1996. Effects of rain intensity on splash dispersal of Colletotrichum acutatum. Phytopathology 86:864-874.

15. McInnes, T. B., Black, L. L., and Gatti, J. M., Jr. 1992. Disease-free plants for management of strawberry anthracnose crown rot disease. Plant Dis. 76:260-264.

16. Norman, D. J., and Strandberg, J. O. 1997. Survival of Colletotrichum acutatum in soil and plant debris of leatherleaf fern. Plant Dis. 81:1177-1180.

17. Ntahimpera, N., Wilson, L. L., Ellis, M. A., and Madden, L. V. 1999. Comparison of rain effects on splash dispersal of three Colletotrichum species infecting strawberry. Phytopathology 89:555-563.

18. Rodriguez, R. J., and Yoder, O. C. 1991. A family of conserved repetitive DNA elements from the fungal plant pathogen Glomerella cingulata (Colletotrichum lindemuthianum). Exp. Mycol. 15:232-242.

19. Sambrook, J., Fritsch, E. F., and Maniatis, T. 1989. Molecular Cloning. A Laboratory Manual. 2nd ed. Cold Spring Harbor Press, Cold Spring Harbor, NY.
20. Strand, L. L. 1994. Integrated Pest Management for Strawberries. Publ. \#3351, University of California, Oakland.

21. Sztejnberg, A., Freeman, S., Chet, I., and Katan, J. 1987. The control of Rosellinia ne catrix in soil and in apple orchard by solarization and Trichoderma harzianum. Plant Dis. 71:365-369.

22. Tu, J. C. 1985. An improved Mathur's medium for growth, sporulation and germination of Colletotrichum lindemuthianum. Microbiosis 44:87-93.

23. Ureña-Padilla, A. R., Mitchell, D. J., and Legard, D. E. 2001. Oversummer survival of inoculum of Colletotrichum crown rot in buried strawberry crown tissue. Plant Dis. 85:750-754.

24. Vizvary, M. A., and Warren, H. L. 1983. Survival of Colletotrichum graminicola in soil. Phytopathology 72:522-525.

25. Wilson, L. L., Madden, L. V., and Ellis, M. A. 1992. Overwinter survival of Colletotrichum acutatum in infected strawberry fruit in Ohio. Plant Dis. 76:948-950.

26. Yoshida, S., and Shirata, A. 1999. Survival of Colletotrichum dematium in soil and infected mulberry leaves. Plant Dis. 83:465-468. 